\title{
Ameliorative Effect of Sesamin in Cisplatin-Induced Nephrotoxicity in Rats by Suppressing Inflammation, Oxidative/Nitrosative Stress, and Cellular Damage
}

\author{
Badreldin H. ALI ${ }^{1}$, Suhail AL SALAM ${ }^{2}$, Yousuf AL SULEIMANI ${ }^{1}$, Mohamed AL ZA'ABI, \\ Mohammed ASHIQUE ${ }^{1}$, Priyadarsini MANOJ ${ }^{1}$, Manjusha SUDHADEVI ${ }^{2}$, Mohammed AL \\ TOBI $^{3}$, Abderrahim NEMMAR ${ }^{4}$
}

${ }^{1}$ Department of Pharmacology and Clinical Pharmacy, College of Medicine and Health Sciences, Sultan Qaboos University, Muscat, Oman, ${ }^{2}$ Department of Pathology, College of Medicine and Health Sciences, United Arab Emirates University, Al Ain, United Arab Emirates, ${ }^{3}$ Department of Biochemistry and Clinical Pharmacy, College of Medicine and Health Sciences, Sultan Qaboos University, Muscat, Oman, ${ }^{4}$ Department of Physiology, College of Medicine and Health Sciences, United Arab Emirates University, Al Ain, United Arab Emirates

Received February 14, 2019

Accepted October 15, 2019

Epub Ahead of Print December 19, 2019

\begin{abstract}
Summary
Nephrotoxicity of cisplatin (CP) involves renal oxidative stress and inflammation, and sesamin (a major liganin in many plants) has strong antioxidant and antiinflammatory actions. Therefore, we investigated here the possible mitigative action of sesamin on $\mathrm{CP}$ nephrotoxicity in rats. Sesamin was given orally ( $5 \mathrm{mg} / \mathrm{kg} /$ day, 10 days), and on the $7^{\text {th }}$ day, some of the treated rats were injected intraperitoneally with either saline or $\mathrm{CP}(5 \mathrm{mg} / \mathrm{kg})$. On the $11^{\text {th }}$ day, rats were sacrificed, and blood and urine samples and kidneys were collected for biochemical estimation of several traditional and novel indices of renal damage in plasma and urine, several oxidative and nitrosative indices in kidneys, and assessment of histopathological renal damage. CP significantly and adversely altered all the physiological, biochemical and histopathological indices of renal function measured. Kidneys of $\mathrm{CP}$-treated rats had a moderate degree of necrosis. This was markedly lessened when CP was given simultaneously with sesamin. Sesamin treatment did not significantly alter the renal $\mathrm{CP}$ concentration. The results suggested that sesamin had ameliorated CP nephrotoxicity in rats by reversing the $\mathrm{CP}$-induced oxidative stress and inflammation. Pending further pharmacological and toxicological studies sesamin may be considered a potentially useful nephroprotective agent.
\end{abstract}

\section{Key words}

Cisplatin • Nephrotoxicity • Sesame oil • Sesamin • Rats

\section{Corresponding author}

B. H. Ali, Department of Pharmacology, College of Medicine, Sultan Qaboos University, P. O. Box 35 Al Khod, Postal code 123, Oman. E-mail: akthmali@squ.edu.om

\section{Introduction}

Cisplatin (CP) is a major and potent platinumbased antineoplastic agent that is used in the treatment of a wide range of cancers, including otherwise resistant solid tumors. It is currently among the most widely used agents in the chemotherapy of lymphomas, stomach, esophageal, pancreatic, bladder, head and neck, lung, ovarian, and testicular cancers (Dasari and Tchounwou 2016, Ojima et al. 2018). Nephrotoxicity is known to be the dose-limiting side effect of CP-based chemotherapy in cancer patients that leads to acute kidney injury (AKI), followed by chronic renal problems (Latcha et al. 2016, Skinner 2018). CP-induced AKI is a complex process, and has often poor prognosis (Sharp and Siskind 2017). Wider usage of CP is hampered by nephrotoxicity, as about $25-40 \%$ of the cancer patients exhibit a progressive

PHYSIOLOGICAL RESEARCH • ISSN 1802-9973 (online) 
decline in renal function after one dose of $\mathrm{CP}$, and more than $70 \%$ of children given $\mathrm{CP}$ experience renal dysfunction (Hoek et al. 2016, Karasawa and Steyger 2015).

Currently, there are no completely effective approaches available to prevent $\mathrm{CP}$ nephrotoxicity during chemotherapy (Crona et al. 2017). Although the pathogenesis of $\mathrm{CP}$ nephrotoxicity is not entirely clear, it is known that $\mathrm{CP}$ activates multiple signaling pathways in renal tubular cells, leading to inflammation, oxidative stress, tubular cell injury, and death (Karasawa and Steyger 2015, Zhu et al. 2015).

Various strategies, including the use of drugs and phytochemical supplements, have been attempted to either ameliorate or prevent CP nephrotoxicity (HeidariSoreshjani 2017, Crona 2017). These include naturallyoccurring and synthetic antioxidants, modulators of nitric oxide, diuretics, cytoprotective and antiapoptotic agents (Ali and Al Moundhri 2006, Pabla and Dong 2008, Nematbakhsh et al. 2017). Data from animal and limited human studies suggest that use of these approaches may improve oncological outcomes and mitigate toxicity (Prasad 2004).

Sesame seeds and oil have been widely used in human diet as a healthy food for thousands of years (Namiki 2007, Guo et al. 2016). Sesame oil has also been utilized in traditional medicine in, for example, India and the Middle East (Namiki 2007). Sesamin is the most abundant lignan in sesame oil, usually about $0.4 \%$ (Fukuda et al. 1998, Namiki 2007). It has antiinflammatory (Fan et al. 2017a), antioxidant (Wan et al. 2015, and antiapoptotic (Fan et al. 2017b) actions. As CP nephrotoxicity involves inflammation, oxidative stress and apoptosis (Pabla and Dong et al. 2008, Sharp and Siskind 2017), we thought it worthwhile testing whether sesamin, at a safe dose that have been successfully used before (Tomimori et al. 2017), could ameliorate CP-induced nephrotoxicity.

\section{Methods}

\section{Ethics statement}

Ethical approval for conducting the work was obtained from Sultan Qaboos University (SQU) Animal Ethics Committee (SQU/AEC/2017-15). All procedures involving animals and their care were carried out in accordance with international laws and policies (EEC Council directives 2010/63/EU, 22 September, 2010 and NIH Guide for the Care and Use of Laboratory Animals,
NIH Publications, $8^{\text {th }}$ edition, 2011).

\section{Chemicals}

Sesamin, carboxymethyl cellulose and platinum standard solution were purchased from Sigma-Aldrich Corporation (St. Louis, MO, USA), CP from Mylan S.A.S. (Saint-Priest, France), and tumor necrosis factor alpha (TNF- $\alpha$ ), cystatin $C$, interleukin-1 $\beta$ (IL-1 $\beta$ ), transforming growth factor (TGF- $\beta 1$ ) and neutrophil gelatinase-associated lipocalin (NGAL) ELISA kits from Thermo Fisher Scientific, Inc. (Waltham, MA, USA). Renalase ELISA kit was purchased from Cusabio Biotech Co., Ltd. (Wuhan, Hubei Province, P. R. China), and superoxide dismutase (SOD), catalase (CAT), glutathione reductase (GR), total antioxidant capacity (TAC), and malondialdehyde (MDA) assay kits from BioVision, Inc. (Milpitas, CA, USA). Total nitrite oxide assay kit, T-cell immunoglobulin and mucin domain 1 (TIM-1) or kidney injury molecule-1 (KIM-1), and liver-type fatty acidbinding protein (L-FABP) ELISA kits were purchased from R\&D Systems, Inc. (Minneapolis, MN, USA). $N$-acetyl- $\beta$-D-glucosaminidase (NAG) was obtained from Diazyme Laboratories, Inc. (Poway, CA, USA), and myeloperoxidase (MPO) assay kit from Abcam, Inc. (Cambridge, UK). Nuclear factor erythroid 2-related factor 2 (Nrf2) ELISA kit was obtained from Cloud Clone Corp. (Katy, TX, USA). Urea, creatinine, uric acid, calcium, phosphorus and albumin were measured using an automated biochemical analyzer, Mindray BS-120 chemistry analyzer, from Shenzhen Mindray Bio-Medical Electronics Co. (Shenzhen, P. R. China).

\section{Animals and treatments}

Male Wistar rats, eight-weeks old and weighing about $200 \mathrm{~g}$ were obtained from Sultan Qaboos University Small Animal House. The rats $(n=36)$ were given free access to water, and a standard nutritionallyadequate laboratory chow diet (Oman Flour Mills, Muscat, Oman). They were kept at an ambient temperature of $22 \pm 2{ }^{\circ} \mathrm{C}$, humidity of $60 \%$ and maintained at $12 \mathrm{~h} / 12 \mathrm{~h}$ light: dark cycle (light from 6:00 to $18: 00)$.

Two experiments were conducted as follows:

A. After five days of acclimatization, the rats were randomly assigned to four groups and treated as follows:

1) The first (Control) received oral saline $(0,4 \mathrm{ml} / \mathrm{kg})$ only for 10 consecutive days.

2) The second group was treated as in group one, but also injected intraperitoneally (i.p.) with $\mathrm{CP}$ at a dose 
of $5 \mathrm{mg} / \mathrm{kg}$, once on the $7^{\text {th }}$ day of treatment.

3) The third group was treated as in group one, but also given sesamin ( $5 \mathrm{mg} / \mathrm{kg} /$ day) orally for 10 days.

4) The fourth group was treated with sesamin ( $5 \mathrm{ml} / \mathrm{kg} /$ day) orally for 10 days, and CP on the $7^{\text {th }}$ day of treatment, as in the second group.

B. A similar experiment was carried out in which sesamin was replaced with sesame oil $(5 \mathrm{ml} / \mathrm{kg} /$ day $)$ orally for 10 days, and CP was injected i.p. on the $7^{\text {th }}$ day.

The doses of sesamin, sesame oil, and CP were selected encompassing doses mentioned in previously published studies, (Soliman et al. 2014, Tomimori et al. 2017, Ali et al. 2011, respectively).

One day before the rats were killed, urine of each rat was collected over a 24-hr period, and its volume measured. Immediately after the end of the treatment period, rats were anesthetized with a combination of ketamine $(60 \mathrm{mg} / \mathrm{kg})$ and xylazine $(5 \mathrm{mg} / \mathrm{kg})$ given i.p. Blood was then collected from the inferior vena cava in heparinized tubes and centrifuged at $900 \mathrm{x}$ g for $15 \mathrm{~min}$, at $5{ }^{\circ} \mathrm{C}$ to separate plasma. The plasma harvested was stored frozen at $-80{ }^{\circ} \mathrm{C}$ pending biochemical analyses within ten days. The rats were then sacrificed by an overdose of anesthesia. The kidneys were removed from the rats, washed with ice-cold saline, blotted with a piece of filter paper and weighed. A small piece from the left kidney was fixed in $10 \%$ buffered formalin. The cortex of the right kidney was excised from the medulla. Part was stored immediately deep frozen at $-80^{\circ} \mathrm{C}$ for measuring platinum concentration and part was rapidly homogenized in ice-cold saline to produce $10 \%(\mathrm{w} / \mathrm{v})$ tissue homogenate for other biochemical measurements.

\section{Biochemical analysis}

Plasma urea, creatinine, uric acid, calcium $(\mathrm{Ca})$, phosphorus (P) and urine albumin and creatinine were measured by an autoanalyzer, as described before (Al Suleimani et al. 2017). Plasma TNF- $\alpha$, cystatin-C, IL-1 $\beta$, renalase and NGAL were measured using ELISA kits.

Kidney SOD, CAT, GR, TAC, nitrite, nitrate and total nitric oxide (NO) as well as urinary albumin, creatinine and urine albumin-to-creatinine ratio UACR), kidney injury molecule-1 (KIM-1), fatty acids -binding proteins (FABP), and N-acetyl- $\beta$-D-glucosaminidase (NAG) activity were measured as described before using spectrophotometry and ELISA kits (Ali et al. 2013, Ali et al. 2018).

\section{Measurement of plasma platinum concentration}

The concentration of CP (as platinum) in plasma was measured by a standard method of inductively coupled plasma atomic emission spectrometry using an emission wavelength of $265.945 \mathrm{~nm}$, at the Central Analytical and Applied Research Unit, College of Science, SQU, Oman. Platinum atomic absorption spectrophotometer standard solution was used to construct the standard curve.

\section{Histopathological analysis}

Kidneys were excised, washed with ice-cold saline, blotted with filter paper and weighed. Each kidney was cassetted and fixed directly in $10 \%$ neutral formalin for $24 \mathrm{~h}$, which was followed by dehydration in increasing concentrations of ethanol, clearing with xylene and embedding in paraffin. Sections ( $4 \mu \mathrm{m}$ thick) were prepared from paraffin blocks and stained with hematoxylin and eosin (H\&E). The stained sections were evaluated blindly using light microscopy. The extent of necrosis was measured using Image $\mathrm{J}$ software (NIH, USA).

\section{Statistical analysis}

Data were given as mean \pm SEM, and were analyzed by one-way analysis of variance followed by Bonferroni 's multiple comparison test (GraphPad Prism version 5.03, San Diego, CA, USA); $P<0.05$ was considered statistically significant.

\section{Results}

\section{Physiological findings}

$\mathrm{CP}$ treatment caused a significant reduction in the body-weight of the rats and a significant rise in their kidney weight, relative to the body-weight, and in their urinary output $24 \mathrm{~h}$ after the end of treatment $(P<0.05)$. These changes were significantly mitigated when sesamin was given concomitantly with CP. Treatment with sesamin alone did not cause significant changes in the above parameters (Table 1).

\section{Plasma biochemical indices of renal damage}

As shown in Table 2, CP treatment significantly increased creatinine, urea and uric acid, and $\mathrm{P}$ concentrations, and decreased that of $\mathrm{Ca}$ in plasma, when compared with the control values. CP also increased the activity of the enzyme NGAL. Sesamin was without any significant effect on these analytes. Sesamin 
given together with $\mathrm{CP}$ significantly mitigated the actions of CP mentioned above.

Urinary biochemical indices of renal function These results are shown in Table 3. CP treatment significantly increased the urinary concentrations of KIM and L-FABP, NAG activity, and the urine albumin-tocreatinine ratio $(P<0.05)$. $\mathrm{CP}$ treatment significantly decreased creatinine clearance $(P<0.05)$.

Table 1. Effect of treatment with sesamin (SM) on some physiological parameters in rats with cisplatin (CP)-induced acute kidney injury (AKI).

\begin{tabular}{lcccc}
\hline Parameters/Treatment & Control & CP (5 mg/kg) & SM (5 mg/kg) & CP + SM \\
\hline Change in body weight (\%) & $16.77 \pm 1.29$ & $8.44 \pm 1.76^{\mathbf{a}}$ & $20.07 \pm 1.10$ & $14.94 \pm 0.99^{\mathbf{b}}$ \\
Relative kidney weight (\%) & $0.58 \pm 0.01$ & $0.69 \pm 0.03^{\mathbf{a}}$ & $0.57 \pm 0.01$ & $0.62 \pm 0.01^{\mathbf{b}}$ \\
Urine flow ( $\mu$ l/min) & $6.25 \pm 0.36$ & $9.95 \pm 0.66^{\mathbf{a}}$ & $5.67 \pm 0.42$ & $8.68 \pm 0.61^{\mathbf{a}}$ \\
Food intake (g) & $21.33 \pm 1.20$ & $17.20 \pm 2.14^{\mathbf{a}}$ & $21.63 \pm 1.13$ & $19.30 \pm 0.48$ \\
Feces output $(g)$ & $8.17 \pm 0.91$ & $5.97 \pm 0.76^{\mathbf{a}}$ & $9.70 \pm 0.80$ & $6.82 \pm 0.40$ \\
\hline
\end{tabular}

The values in the tables are mean \pm SEM $(n=6)$. Sesamin $(5 \mathrm{mg} / \mathrm{kg} /$ day) was given to the rats by oral gavage for 10 days, and on the $7^{\text {th }}$ day, AKI was induced by injecting a single dose of CP $(5 \mathrm{mg} / \mathrm{kg})$, intraperitoneally. On the $10^{\text {th }}$ day of treatment, the rats were placed in metabolic cages to collect urine. The rats were sacrificed on the $11^{\text {th }}$ day. Different superscripts indicate significance as follows $\left(P<0.05\right.$ was considered significant): ${ }^{\mathbf{a}}$ denotes significance of Control group vs. different groups, ${ }^{\mathbf{b}}$ denotes significance of $\mathrm{CP}$ group vs. $(\mathrm{CP}+\mathrm{SM})$-treated group.

Table 2. Effect of treatment with sesamin (SM) on some indices of renal damage in plasma of rats with cisplatin (CP)-induced acute kidney injury (AKI).

\begin{tabular}{lcccc}
\hline Parameters/Treatment & Control & CP (5 mg/kg) & SM (5 mg/kg) & CP + SM \\
\hline NGAL $(\mathrm{ng} / \mathrm{ml})$ & $27.36 \pm 2.27$ & $138.86 \pm 9.05^{\mathbf{a}}$ & $30.76 \pm 2.81$ & $95.06 \pm 7.26^{\mathbf{a}, \mathbf{b}}$ \\
Creatinine $(\mu \mathrm{mol} / \mathrm{l})$ & $18.35 \pm 1.08$ & $121.37 \pm 7.72^{\mathbf{a}}$ & $14.88 \pm 0.54$ & $56.72 \pm 2.48^{\mathbf{a , b}}$ \\
Urea $(\mathrm{mmol} / \mathrm{l})$ & $5.70 \pm 0.37$ & $13.42 \pm 0.81^{\mathbf{a}}$ & $4.76 \pm 0.24$ & $9.88 \pm 0.57^{\mathbf{a}, \mathbf{b}}$ \\
Uric acid $(\mu \mathrm{mol} / \mathrm{l})$ & $46.67 \pm 3.85$ & $89.97 \pm 5.75^{\mathbf{a}}$ & $38.95 \pm 2.22$ & $67.28 \pm 5.56^{\mathbf{a}, \mathbf{b}}$ \\
Phosphorus $(\mathrm{mmol} / \mathrm{l})$ & $0.55 \pm 0.05$ & $1.27 \pm 0.12^{\mathbf{a}}$ & $0.54 \pm 0.05$ & $0.89 \pm 0.05^{\mathbf{a , b}}$ \\
Calcium $(\mathrm{mmol} / \mathrm{l})$ & $1.15 \pm 0.06$ & $0.69 \pm 0.05^{\mathbf{a}}$ & $1.03 \pm 0.09$ & $0.92 \pm 0.05^{\mathbf{a}, \mathbf{b}}$ \\
\hline
\end{tabular}

The values in the tables are mean \pm SEM $(n=6)$. Sesamin $(5 \mathrm{mg} / \mathrm{kg} /$ day) was given to the rats by oral gavage for 10 days, and on the $7^{\text {th }}$ day, AKI was induced by injecting a single dose of cisplatin $(5 \mathrm{mg} / \mathrm{kg})$, intraperitoneally. NGAL: Neutrophil gelatinase-associated lipocalin. Different superscripts indicate significance as follows $\left(P<0.05\right.$ was considered significant): ${ }^{a}$ denotes significance of Control group vs. different groups, ${ }^{\mathbf{b}}$ denotes significance of $\mathrm{CP}$ group vs. (CP + SM)-treated group.

Table 3. Effect of treatment with sesamin (SM) on some urinary indices in rats with cisplatin (CP)-induced acute kidney injury (AKI).

\begin{tabular}{lcccc}
\hline Parameters/Treatment & Control & CP (5 $\mathbf{~ m g / k g})$ & SM (5 mg/kg) & CP $+\mathbf{S M}$ \\
\hline KIM-1 (pg/ml) & $221.64 \pm 13.08$ & $532.40 \pm 6.86^{\mathbf{a}}$ & $202.09 \pm 20.61$ & $399.69 \pm 21.05^{\mathbf{a}, \mathbf{b}}$ \\
L-FABP $(\mathrm{ng} / \mathrm{ml})$ & $0.82 \pm 0.07$ & $6.83 \pm 0.38^{\mathbf{a}}$ & $0.90 \pm 0.10$ & $5.35 \pm 0.32^{\mathbf{a}, \mathbf{b}}$ \\
NAG activity (IU/l) & $3.16 \pm 0.27$ & $14.72 \pm 0.84^{\mathbf{a}}$ & $1.12 \pm 0.19^{\mathbf{a}}$ & $5.26 \pm 0.34^{\mathbf{a}, \mathbf{b}}$ \\
Creatinine clearance (ml/min) & $3.10 \pm 0.22$ & $0.54 \pm 0.04^{\mathbf{a}}$ & $3.24 \pm 0.20$ & $1.28 \pm 0.10^{\mathbf{a}, \mathbf{b}}$ \\
UACR (mg/mmol) & $423.89 \pm 10.55$ & $789.83 \pm 27.36^{\mathbf{a}}$ & $405.33 \pm 13.13$ & $571.16 \pm 28.84^{\mathbf{a}, \mathbf{b}}$ \\
\hline
\end{tabular}

Values in the table are means \pm SEM $(n=6)$. Sesamin $(5 \mathrm{mg} / \mathrm{kg} /$ day) was given to the rats by oral gavage for 10 days, and on the $7^{\text {th }}$ day, AKI was induced by injecting a single dose of cisplatin $(5 \mathrm{mg} / \mathrm{kg})$, intraperitoneally. On the $10^{\text {th }}$ day of treatment, the rats were placed in metabolic cages to collect urine. KIM-1: Kidney injury molecule-1; L-FABP: Liver-type fatty acid-binding protein; NAG: $N$-acetyl- $\beta$-D-glucosaminidase (NAG); UACR: Urine albumin-to-creatinine ratio. Different superscripts indicate significance as follows $\left(P<0.05\right.$ was considered significant): ${ }^{a}$ denotes significance of Control group vs. different groups, ${ }^{\mathbf{b}}$ denotes significance of CP group vs. $(\mathrm{CP}+\mathrm{SM})$-treated group. 


\section{Inflammatory biomarkers in plasma}

The results are shown in Figure 1. CP treatment significantly increased the concentrations of TNF- $\alpha$, cystatin C, IL-1 $\beta$, TGF- $\beta 1$, and MPO activity, and significantly decreased that of renalase $(P<0.001)$. These actions were significantly mitigated when sesamin was given with CP. Treatment with sesamin alone did not significantly affect any of these analytes.

\section{Plasma platinum concentrations}

The concentration of platinum in the plasma (in ppm) from cisplatin-treated rats was $0.063 \pm 0.009$, and $0.056 \pm 0.003$ in the plasma from rats treated with cisplatin and sesamin $(P>0.1)$. The insignificant reduction in the latter group amounted to about $11 \%$.

Oxidative and nitrosative stress indices in renal homogenates

The results of the oxidative stress are depicted in Figure 2. CP treatment significantly decreased the activities of SOD, CAT and GR, and TAC concentration $(P<0.0001$, except for the result of CAT, which was at the level of $P<0.05$ ). Treatment with sesamin alone significantly increased renal SOD activity $(P<0.0001)$, and slightly and insignificantly increased the levels of the other analytes. CP treatment significantly increased the Nrf2 and MDA concentrations $(P<0.0001)$, an action that was significantly reversed by concomitant treatment with sesamin $(P<0.0001)$.

The results on the nitrosative stress are shown in Figure 3. CP significantly increased the renal nitrate concentration and the nitrate/nitrite ratio $(\mathrm{P}<0.05)$. Concomitant sesamin treatment to $\mathrm{CP}$ - treated rats significantly decreased the nitrate/nitrite ratio $(\mathrm{P}<0.05)$ to control level.

\section{Renal histopathology}

The results of renal histopathology examinations are presented in Figure 4 and Table 4. The control group (saline IP) showed normal kidney architecture and histology (score 0) (Fig. 4A, B). The cisplatin (IP) treated group, showed acute tubular necrosis in $52 \pm 3.6 \%$ of examined tissue areas (score 3), showing tubular distention with necrotic material involving loss of brush border, tubular dilatation, tubular cells necrosis, tubular nuclear pyknosis, tubular nuclear enlargement with hyperchromasia, tubular cells flattening, macrophages within the lumen, epithelial cells within the lumen and intra-luminal eosinophilic material (Fig. 4C, D). The sesamin-treated group showed normal kidney architecture and histology (score 0) (Fig. 4E, F). The (cisplatin + sesamin)-treated group showed dramatic improvement in the histological appearance when compared with the cisplatin-treated group. There was no morphological evidence of acute tubular necrosis in the examined areas (score 0) (Fig. 4G, H).

\section{Sesame oil}

Sesame oil, at the dose used, did not significantly alter any of the parameters studied in the sesamin experiment described above (data not shown).
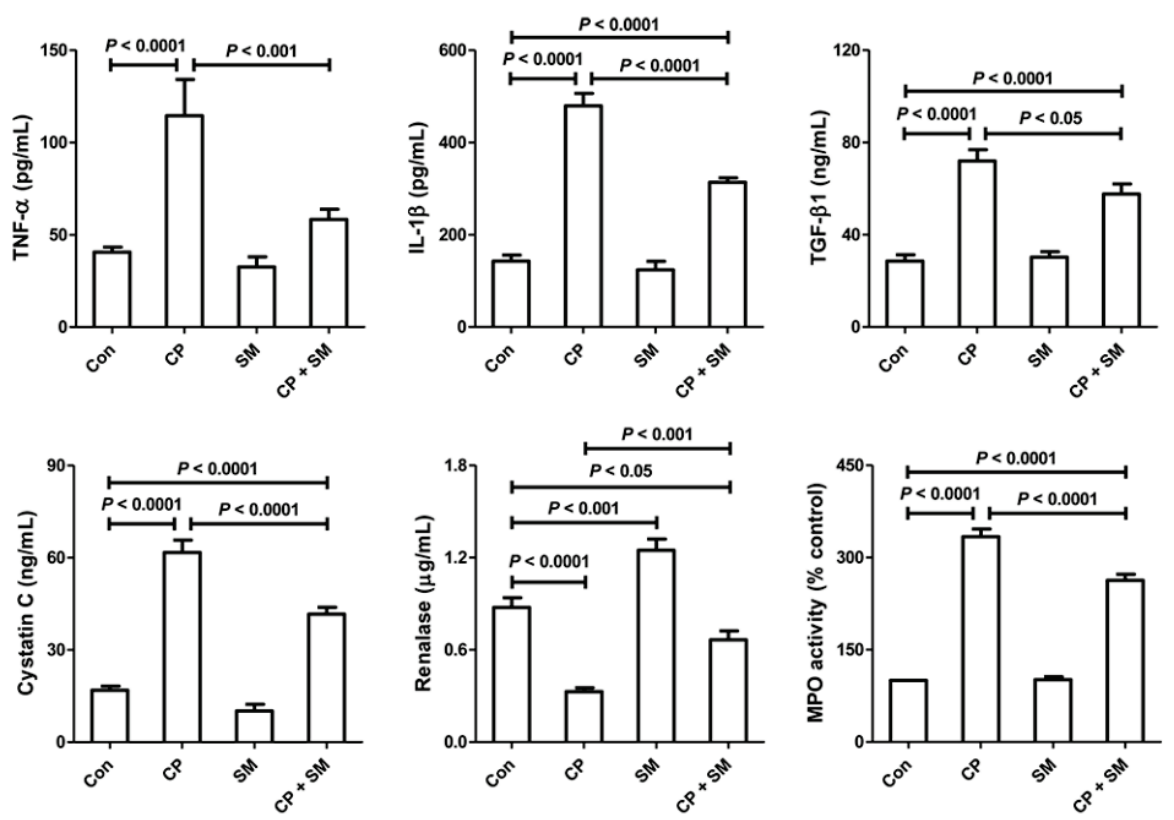

Fig. 1. The plasma concentration of tumor necrosis factor (TNF-a), interleukin (IL-1 $\beta)$, transforming growth factor (TGF- $\beta 1$ ), cystatin $C$, renalase, and the renal activity of myeloperoxidase (MPO) in control rats, and rats treated with cisplatin or sesamin (separately or in combination). Each column and vertical bar represents mean \pm SEM $(n=6)$. Differences between the groups were assessed by one-way analysis of variance (ANOVA) followed by Bonferroni's multiple comparison test. 

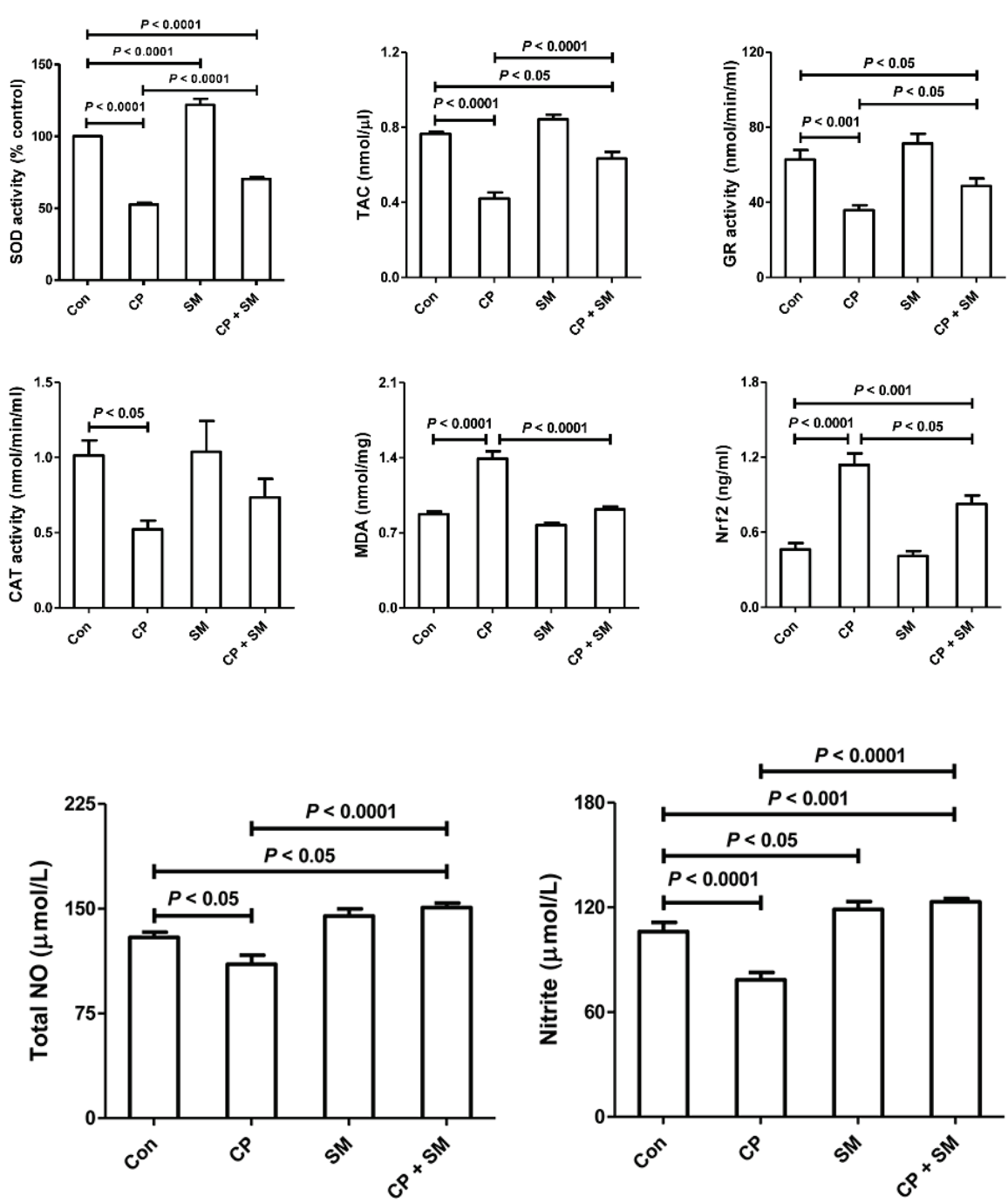

Fig. 3. The renal concentration of total nitric oxide (NO), nitrite and nitrate, and the nitrate/nitrite ratio in control rats, and rats treated with cisplatin or sesamin (separately or in combination). Each column and vertical bar represents mean \pm SEM $(n=6)$. Differences between the groups were assessed by one-way analysis of variance (ANOVA) followed by Bonferroni's multiple comparison test.

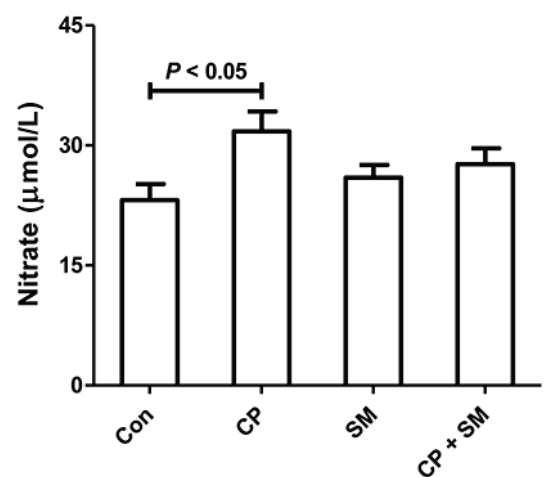

\section{Discussion}

In this work, we have found that sesamin $(5 \mathrm{mg} / \mathrm{kg})$ was highly and significantly effective in mitigating the physiological, biochemical and histopathological damage induced by $\mathrm{CP}$, without causing any overt adverse effects.

Sesame oil, at the dose used, did not significantly alter any of the parameters studied in the sesamin experiment described above. Raw sesame oil contains $0.5-1.1 \%$ sesamin (Mahendra Kumar and Singh 2015). The low amount of sesamin the oil may account for its inability to mitigate the indices of renal damage caused $\mathrm{CP}$.

$\mathrm{CP}$ is considered the cornerstone of therapy for many types of solid tumors (Crona et al. 2017). Despite 
many studies, the mechanisms underlying the side effects induced by $\mathrm{CP}$ are not fully elucidated, but have been suggested to be multi-factorial in nature (Miller et al. 2010, Wilmes et al. 2015). These mechanisms include the generation of reactive oxygen and nitrogen species, inflammation and apoptosis. The former interferes with the antioxidant defense system and causes oxidative damage in tissues, and reaction with thiols in protein and glutathione, leading to cell dysfunction. Inflammation could be instigated by damage to the renal epithelial cells, and may augment renal injury and dysfunction in vivo (Miller et al. 2010).
In this work, injection of rats with $\mathrm{CP}(5 \mathrm{mg} / \mathrm{kg})$ caused a significant decrease in total body weight as well as an increase in kidney/body weight ratio when compared with the control group. The decrease in body weight seen in the $\mathrm{CP}$-treated rats may be due to the gastrointestinal toxicity of the drug (Shahid et al. 2018) or possibly to the injured renal tubules, and the consequent inability of the tubular cells to reabsorb water, increased urine volume voided leading to dehydration and loss of body weight (Ali et al. 2008). This renal tubular damage resulted in acute nephrotoxicity reflected in the significant changes in the physiological, biochemical and
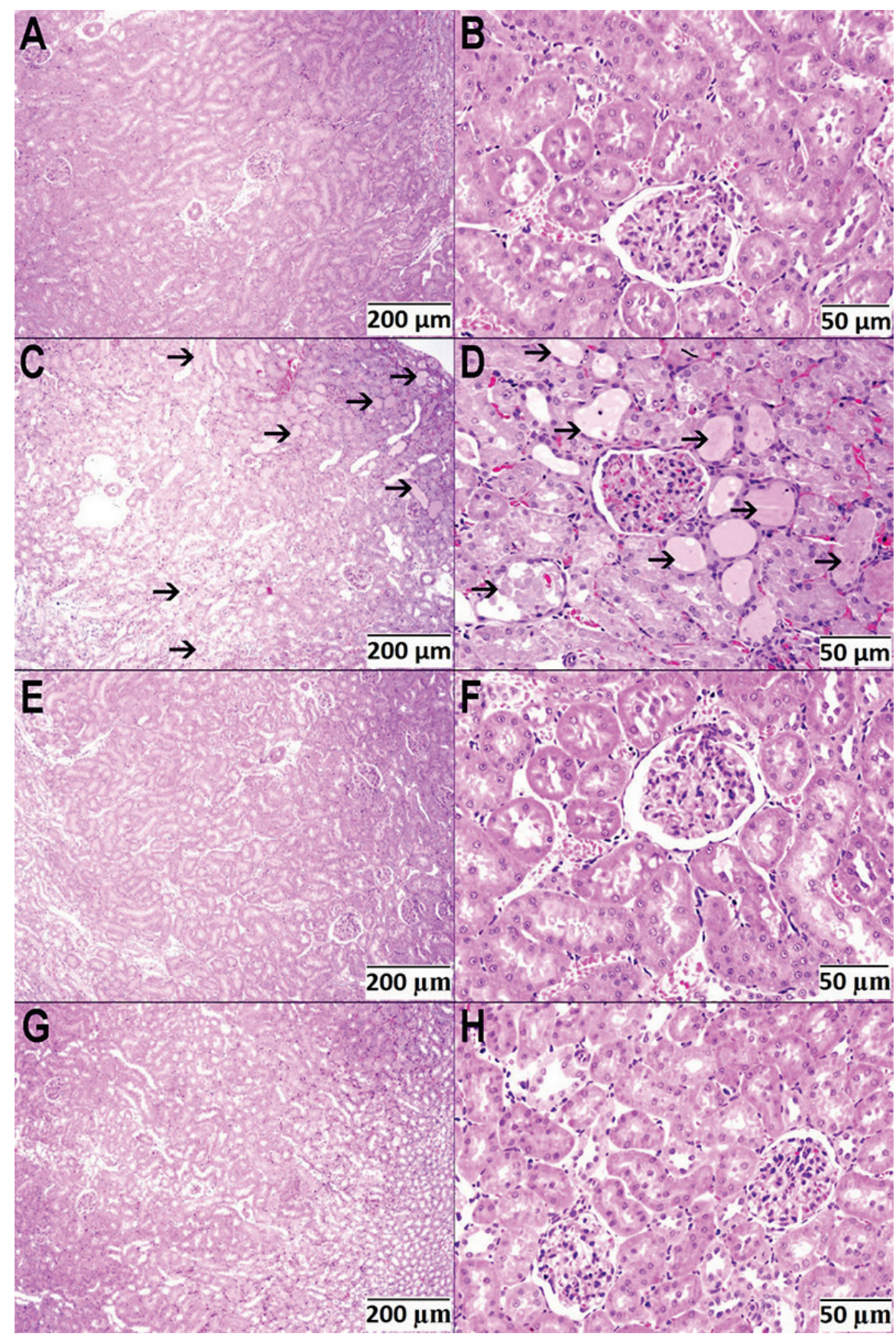

Fig. 4. Representative micrographs of kidney sections from control rats, and rats treated with cisplatin or sesamin (separately or in combination), stained with hematoxylin and eosin ( $\mathrm{H} \& \mathrm{E})$. The control (A and $\mathbf{B}$ ) and sesamintreated group (E and $\mathbf{F}$ ) show normal kidney architecture and histology. The cisplatin-treated group (C and $\mathbf{D}$ ) shows acute tubular necrosis in $52 \pm 3.62 \%$ of examined tissue areas (thin arrows) with tubular distention with necrotic material. The (cisplatin + sesamin)-treated group (G and $\mathbf{H}$ ) shows dramatic improvement in the histologic appearance with absence of acute tubular necrosis and complete recovery of injured tubules. 
Table 4. Effect of treatment with sesamin (SM) on necrosis in the kidneys of rats with cisplatin (CP)-induced acute kidney disease (AKD).

\begin{tabular}{|c|c|c|c|c|}
\hline Parameters/Treatment & Control & CP (5 mg/kg) & SM (5 mg/kg) & $\mathrm{CP}+\mathrm{SM}$ \\
\hline Percentage of necrosis & $0.0 \pm 0.0$ & $52.0 \pm 3.6^{\mathbf{a}}$ & $0.0 \pm 0.0$ & $0.0 \pm 0.0^{\mathbf{b}}$ \\
\hline Score of necrosis & $0.0 \pm 0.0$ & $3.0 \pm 0.0^{\mathrm{a}}$ & $0.0 \pm 0.0$ & $0.0 \pm 0.0^{\mathbf{b}}$ \\
\hline
\end{tabular}

The values in the tables are mean $\pm \operatorname{SEM}(\mathrm{n}=6)$. Different superscripts indicate significance as follows, where $P<0.05:{ }^{a}$ denotes significance of control group vs. different groups, ${ }^{\mathbf{b}}$ denotes significance of CP group vs. (CP + SM)-treated group.

damage resulted in acute nephrotoxicity reflected in the significant changes in the physiological, biochemical and other indices, as previously reported (Ali et al. 2014, Ali et al. 2018). These results were supported by light microscopic examination of renal tissues that showed clear pathological changes. Renal structure and function were significantly improved by treatment with sesamin $(5 \mathrm{mg} / \mathrm{kg})$.

Among the mechanisms involved in sesamin amelioration of CP-induced nephrotoxicity, are the significant reduction in oxidative and nitrosative stress, apoptosis and inflammation. Oxidative stress is known to have a critical and causal role in CP-induced nephrotoxicity and that it mediates a rise in lipid peroxidation, which is a reliable oxidative stress marker, and nitric oxide increases inflammation and oxidative processes (Meng et al. 2017). Sesamin at the relatively low dose used here was effective in significantly abrogating these actions, confirming its strong antioxidant actions. CP is taken up in renal tubular cells in high concentrations, leading to its accumulation and tubular cell injury and death, culminating in acute renal failure (Miller et al. 2010).

We have found that $\mathrm{CP}$ treatment significantly increased the renal content of (Nrf2), an essential homeostasis master regulator of tolerance to redox stress, and this action was mitigated by sesamin administration. The increase in Nrf2 has recently been implicated in the cellular defense against $\mathrm{CP}$ nephrotoxicity (Shelton $e t$ al. 2013).

It has recently been reported that sesamin (at a single dose of $25-100 \mathrm{mg} / \mathrm{kg}$ ) given orally one hour before intraperitoneal injection of lipopolysaccharide (LPS) was effective in protecting mice from LPS-induced acute kidney injury (AKI) by reducing renal oxidative stress, inflammation, and apoptosis (Rousta et al. 2018).

The pathogenesis of $\mathrm{CP}$ nephrotoxicity, involves inflammation as a major factor, and $\mathrm{CP}$ is known to activate the NF- $\kappa B$ pathway, that facilitate the increase in several inflammatory cytokines such as TNF- $\alpha$ and the IL-1 $\beta$. Both cytokines have been increased in our experiment by $\mathrm{CP}$, an action that was significantly antagonized by sesamin treatment. Cystatin, in addition to being a reliable renal biomarker in both acute kidney injury and chronic kidney disease (Ali et al. 2018), is also considered a biomarker for inflammation (Deyà-Martínez et al. 2016).

We used in this work the relatively novel biomarkers TGF- $\beta 1$, which is used as biomarker in cardiovascular diseases (Mukherji et al. 2017), and lately as a biomarker in surgery-induced renal fibrosis in rat (Ma et al. 2018). Here, we found that its concentration in plasma is significantly increased in CP-induced nephrotoxicity, and that sesamin significantly ameliorated that action.

Probably for the first time, we used the activity of the relatively novel enzyme renalase as a biomarker of renal health in rats with $\mathrm{CP}$ nephrotoxicity. Renalase was used before as a biomarker for cardiovascular disease (Schlaich et al. 2018). Here we have found that $\mathrm{CP}$ treatment induces a significant inhibition of the enzyme, whereas sesamin alone causes the opposite action. (Fig. 1). When sesamin was given to CP-treated rats, the enzyme activity was significantly raised to about $80 \%$ of the control value. Our results indicate that plasma renalase activity is negatively correlated with renal health in rats, and is different from results in humans with chronic kidney disease, where a significant increase has been observed. This reason(s) for the difference is not certain, but may be due to species difference (Quelhas-Santos and Pestana 2014, Baek et al. 2017).

Previous studies have shown that some agents can reduce CP-induced nephrotoxicity by decreasing the accumulation of platinum renal levels (Kimoto et al. 2013), and some agents mitigate CP nephrotoxicity without significantly affecting these levels (Ali et al. 2013).

It was of interest to note that the ameliorative action of sesamin on CP nephrotoxicity was not related to 
any possible reduction of $\mathrm{CP}$ accumulation in the plasma, as we found only a slight (about $11 \%$ ) and insignificant reduction in the concentration of platinum in plasma of sesamin-treated rats. It is established that a significant rise in $\mathrm{CP}$ concentrations in the kidneys and plasma occurs in cases of nephrotoxicity (Darwish et al. 2017).

Further experiments are warranted to determine the specific molecular pathways by which the nephroprotective action of sesamin is carried out. Several molecular pathways have previously been suggested to explain the salutary action of sesamin in various experimentally-induced conditions. For example, sesamin has been reported to protect against cardiac remodeling in rodents induced by transverse aortic constriction via the Sirt3/ROS pathway (Fan et al. 2017), several dietary restriction-related signaling pathways, including processes requiring SIRT1, TOR, and AMPK in Caenorhabditis elegans, and the inhibition of the TLR4 expression and NF- $\mathrm{BB}$ activation in LPS-induced acute lung injury in mice (Qiang et al. 2016). NF- $\kappa \mathrm{B}$ activation, toll-like receptor 4 (TLR4), cyclooxygenase-2 (COX2), tumor necrosis factor $\alpha$ (TNF- $\alpha$ ), interleukin-6, DNA fragmentation and Nrf2 have been suggested to be the mechanisms involved in LPS-induced AKI in mice (Rousta et al. 2018).

\section{Conclusions}

The present work has presented experimental evidence that sesamin is useful in mitigating adenineinduced $\mathrm{CKD}$ in rats, through attenuation of several inflammatory, oxidative and nitrosative stress parameters. No overt untoward actions have been found from sesamin treatment. Further studies into the specific molecular mechanism(s) of the beneficial action of sesamin are warranted. Pending further pharmacological and toxicological studies, clinical testing of sesamin as a dietary supplement in patients with AKI and other renal diseases may also be warranted.

\section{Conflict of Interest}

There is no conflict of interest.

\section{Acknowledgements}

Two of the co-authors (BHA and MA) were financially supported by a research grant from the Medical Research Centre, Sultan Qaboos University (IG/DVC/MRC/19/02). We thank Prof. G. Blunden for reading the manuscript, and the researchers at the Central Analytical and Applied Research Unit, College of Science, SQU for their help with measuring platinum in this work.

\section{References}

AL SULEIMANI YM, AL MAHRUQI AS, AL ZA'ABI M, SHALABY A, ASHIQUE M, NEMMAR A, ALI BH: Effect of diesel exhaust particles on renal vascular responses in rats with chronic kidney disease. Environ Toxicol 32: 541-549, 2017. https://doi.org/10.1002/tox.22258

ALI BH, ABDELRAHMAN AM, AL-SALAM S, SUDHADEVI M, ALMAHRUQI AS, AL-HUSSENI IS, BEEGAM S, DHANASEKARAN S, NEMMAR A, AL-MOUNDHRI M: The effect of sildenafil on cisplatin nephrotoxicity in rats. Basic Clin Pharmacol Toxicol 109: 300-308, 2011. https://doi.org/10.1111/j.17427843.2011.00724.x

ALI BH, AL MOUNDHRI MS: Agents ameliorating or augmenting the nephrotoxicity of CP and other platinum compounds: a review of some recent research. Food Chem Toxicol 44: 1173-1183, 2006. https://doi.org/10.1016/j.fct.2006.01.013

ALI BH, RAMKUMAR A, MADANAGOPAL TT, WALY MI, TAGELDIN M, AL-ABRI S, FAHIM M, YASIN J, NEMMAR A: Motor and behavioral changes in mice with cisplatin-induced acute renal failure. Physiol Res 63: 35-45, 2014.

ALI BH, AL-MOUNDHRI M, ELDIN MT, NEMMAR A, AL-SIYABI S, ANNAMALAI K: Amelioration of cisplatininduced nephrotoxicity in rats by tetramethylpyrazine, a major constituent of the Chinese herb Ligusticum wallichi. Exp Biol Med (Maywood) 233: 891-896, 2008. https://doi.org/10.3181/0711-RM-315

ALI BH, AL-SALAM S, AL HUSSEINI IS, AL-LAWATI I, WALY M, YASIN J, FAHIM M, NEMMAR A: Abrogation of cisplatin-induced nephrotoxicity by emodin in rats. Fundam Clin Pharmacol 27: 192-200, 2013. https://doi.org/10.1111/j.1472-8206.2011.01003.x 
ALI BH, AL-SALAM S, AL SULEIMANI Y, AL KALBANI J, AL BAHLANI S, ASHIQUE M, MANOJ P, AL DHAHLI B, AL ABRI N, NASER HT, YASIN J, NEMMAR A, AL ZA'ABI M, HARTMANN C, SCHUPP N: Curcumin ameliorates kidney function and oxidative stress in experimental chronic kidney disease. Basic Clin Pharmacol Toxicol 122: 65-73, 2018. https://doi.org/10.1111/bcpt.12817

ALI BH, CAHLIKOVÁ L, OPLETAL L, KARACA T, MANOJ P, RAMKUMAR A, AL SULEIMANI YM, AL ZA'ABI M, NEMMAR A, CHOCHOLOUSOVA-HAVLIKOVA L, LOCAREK M, SIATKA T, BLUNDEN G: Effect of aqueous extract and anthocyanins of calyces of Hibiscus sabdariffa (Malvaceae) in rats with adenine-induced chronic kidney disease. J Pharm Pharmacol 69: 1219-1229, 2017. https://doi.org/10.1111/jphp.12748

BAEK SH, CHA RH, KANG SW, PARK CW, CHA DR, KIM SG, YOON SA, KIM S, HAN SY, PARK JH, CHANG JH, LIM CS, KIM YS, NA KY: Circulating renalase predicts all-cause mortality and renal outcomes in patients with advanced chronic kidney disease. Korean J Intern Med 34: 858-866, 2017. doi: 10.3904/kjim.2017.058. https://doi.org/10.3904/kjim.2017.058

CRONA DJ, FASO A, NISHIJIMA TF, MCGRAW KA, GALSKY MD, MILOWSKY MI: A systematic review of strategies to prevent cisplatin -induced nephrotoxicity. Oncologist 22: 609-619, 2017. https://doi.org/10.1634/theoncologist.2016-0319

DARWISH MA, ABO-YOUSSEF AM, KHALAF MM, ABO-SAIF AA, SALEH IG, ABDELGHANY TM: Vitamin E mitigates cisplatin-induced nephrotoxicity due to reversal of oxidative /nitrosative stress, suppression of inflammation and reduction of total renal platinum accumulation. J Biochem Mol Toxicol 31: 1-9, 2017. https://doi.org/10.1002/jbt.21833

DASARI S, TCHOUNWOU PB: Cisplatin in cancer therapy: molecular mechanisms of action. Eur J Pharmacol 740 : 364-378, 2014. https://doi.org/10.1016/j.ejphar.2014.07.025

DEYÀ-MARTÍNEZ À, FORTUNY C, SOLER-PALACÍN P, NETH O, SÁNCHEZ E, MARTÍN-NALDA A, FALCÓN-NEYRA L, VILA A, VALLS A, NOGUERA-JULIAN A: Cystatin C: A Marker for inflammation and renal function among HIV-infected children and adolescents. Pediatr Infect Dis J 35: 196-200, 2016. https://doi.org/10.1097/INF.0000000000000960

FAN D, YANG Z, LIU FY, JIN YG, ZHANG N, NI J, YUAN Y, LIAO HH, WU QQ, XU M, DENG W, TANG QZ: Sesamin protects against cardiac remodeling via Sirt3/ROS Pathway. Cell Physiol Biochem 44: 2212-2227, 2017a. https://doi.org/10.1159/000486026

FAN D, YANG Z, YUAN Y, WU QQ, XU M, JIN YG, TANG QZ: Sesamin prevents apoptosis and inflammation after experimental myocardial infarction by JNK and NF- $\mathrm{B}$ pathways. Food Funct 8: 2875-2885, $2017 \mathrm{~b}$. https://doi.org/10.1039/C7FO00204A

FUKUDA N, ZHANG L, KODAMA M, SAKONO M, IDE T, YAMAMOTO K, SUGANO M: Effect of dietary sesamin on metabolic fate of an exogenous linolelaidic acid in perfused rat liver. J Nutr Sci Vitaminol (Tokyo) 45: 437-448, 1999. https://doi.org/10.3177/jnsv.45.437

GUO H, LIU Y, WANG L, ZHANG G, SU S, ZHANG R, ZHANG J, LI A, SHANG C, BI B, LI Z: Alleviation of doxorubicin-induced hepatorenal toxicities with sesamin via the suppression of oxidative stress. Hum Exp Toxicol 35: 1183-1193, 2016. https://doi.org/10.1177/0960327115626581

HEIDARI-SORESHJANI S, ASADI-SAMANI M, YANG Q, SAEEDI-BOROUJENI A: Phytotherapy of nephrotoxicity-induced by cancer drugs: an updated review. J Nephropathol 6: 254-263, 2017. https://doi.org/10.15171/jnp.2017.41

HOEK J, BLOEMENDAL KM, VAN DER VELDEN LA, VAN DIESSEN JN, VAN WERKHOVEN E, KLOP WM, TESSELAAR M: Nephrotoxicity as a dose-limiting factor in a high-dose CP-based chemoradiotherapy regimen for head and neck carcinomas. Cancers (Basel) 8: pii: E21, 2016. https://doi.org/10.3390/cancers8020021

KARASAWA T, STEYGER PS: An integrated view of cisplatin-induced nephrotoxicity and ototoxicity. Toxicol Lett 237: 219-227, 2015. https://doi.org/10.1016/j.toxlet.2015.06.012

KIMOTO Y, NISHINOHARA M, SUGIYAMA A, HARUNA A, TAKEUCHI T: Protective effect of lactoferrin on cisplatin-induced nephrotoxicity in rats. J Vet Med Sci 75: 159-164, 2013. https://doi.org/10.1292/jvms.12$\underline{0154}$ 
LATCHA S, JAIMES EA, PATIL S, GLEZERMAN IG, MEHTA S, FLOMBAUM CD: Long-term renal outcomes after CP treatment. Clin J Am Soc Nephrol 11: 1173-1179, 2016. https://doi.org/10.2215/CJN.08070715

MA L, LI H, ZHANG S, XIONG X, CHEN K, JIANG P, JIANG K, DENG G: Emodin ameliorates renal fibrosis in rats via TGF- $\beta 1 /$ Smad signaling pathway and function study of Smurf 2. Int Urol Nephrol 50: 373-382, 2018. https://doi.org/10.1007/s11255-017-1757-x

MAHENDRA KUMAR C, SINGH SA: Bioactive lignans from sesame (Sesamum indicum L.): evaluation of their antioxidant and antibacterial effects for food applications. J Food Sci Technol 52: 234-241, 2015. https://doi.org/10.1007/s13197-014-1334-6

MENG H, FU G, SHEN J, SHEN K, XU Z, WANG Y, JIN B, PAN H: Ameliorative effect of daidzein on cisplatininduced nephrotoxicity in mice via modulation of inflammation, oxidative stress, and cell death. Oxid Med Cell Longev 2017: 3140680, 2017. https://doi.org/10.1155/2017/3140680

MILLER RP, TADAGAVADI RK, RAMESH G, REEVES WB: Mechanisms of cisplatin nephrotoxicity. Toxins (Basel) 2: 2490-2518, 2010. https://doi.org/10.3390/toxins2112490

MUKHERJI A, ANSARI U, BORGGREFE M, AKIN I, BEHNES M: Clinically relevant biomarkers in acute heart failure: An update. Curr Pharm Biotechnol 18: 482-490, 2017. https://doi.org/10.2174/1389201018666170623090817

NAKATANI Y, YAGUCHI Y, KOMURA T, NAKADAI M, TERAO K, KAGE-NAKADAI E, NISHIKAWA Y: Sesamin extends lifespan through pathways related to dietary restriction in Caenorhabditis elegans. Eur J Nutr 57: 1137-1146, 2018. https://doi.org/10.1007/s00394-017-1396-0

NAMIKI M: Nutraceutical functions of sesame: a review. Crit Rev Food Sci Nutr 47: 651-673, 2007. https://doi.org/10.1080/10408390600919114

NEMATBAKHSH M, PEZESHKI Z, ESHRAGHI JAZI F, MAZAHERI B, MOEINI M, SAFARI T, AZARKISH F, MOSLEMI F, MALEKI M, REZAEI A, SABERI SH, DEHGHANI A, MALEK M, MANSOURI A, GHASEMI M, ZEINALI F, ZAMANI Z, NAVIDI M, JILANCHI S, SHIRDAVANI S, ASHRAFI F: CP-induced nephrotoxicity; protective supplements and gender differences. Asian Pac J Cancer Prev 18: 295-314, 2017.

OJIMA T, NAKAMURA M, NAKAMORI M, KATSUDA M, HAYATA K, MARUOKA S, SHIMOKAWA T, YAMAUE H: Phase I/II trial of chemotherapy with docetaxel, cisplatin, and S-1 for unresectable advanced squamous cell carcinoma of the esophagus. Oncology 95: 116-120, 2018. https://doi.org/10.1159/000488861

PABLA N, DONG Z: CP nephrotoxicity: mechanisms and renoprotective strategies. Kidney Int 73: 994-1007, 2008. https://doi.org/10.1038/sj.ki.5002786

PRASAD KN: Multiple dietary antioxidants enhance the efficacy of standard and experimental cancer therapies and decrease their toxicity. Integr Cancer Ther 3: 310-322, 2004. https://doi.org/10.1177/1534735404270936

QIANG L, YUAN J, SHOUYIN J, YULIN L, LIBING J, JIAN-AN W: Sesamin attenuates lipopolysaccharide-induced acute lung injury by inhibition of TLR4 signaling pathways. Inflammation 39: 467-472, 2016. https://doi.org/10.1007/s10753-015-0270-6

QUELHAS-SANTOS J, PESTANA M: Plasma renalase in chronic kidney disease: differences and similarities between humans and rats. Curr Hypertens Rev 10: 166-170, 2014. https://doi.org/10.2174/1573402111666150108101709

ROUSTA AM, MIRAHMADI SM, SHAHMOHAMMADI A, NOURABADI D, KHAJEVAND-KHAZAEI MR, BALUCHNEJADMOJARAD T, ROGHANI M: Protective effect of sesamin in lipopolysaccharide-induced mouse model of acute kidney injury via attenuation of oxidative stress, inflammation, and apoptosis. Immunopharmacol Immunotoxicol 29: 1-7, 2018. https://doi.org/10.1080/08923973.2018.1523926

SCHLAICH MP, LAMBERT GW, EIKELIS N: Renalase - a potential biomarker for risk of atrial fibrillation? Kardiol Pol 76: 1201-1202, 2018. https://doi.org/10.5603/KP.2018.0163

SHAHID F, FAROOQUI Z, KHAN F: Cisplatin-induced gastrointestinal toxicity: An update on possible mechanisms and on available gastroprotective strategies. Eur J Pharmacol 827: 49-57, 2018. https://doi.org/10.1016/j.ejphar.2018.03.009

SHARP CN, SISKIND LJ: Developing better mouse models to study cisplatin-induced kidney injury. Am J Physiol Renal Physiol 313: F835-F841, 2017. https://doi.org/10.1152/ajprenal.00285.2017 
SHELTON LM, PARK BK, COPPLE IM: Role of Nrf2 in protection against acute kidney injury. Kidney Int 84 : 1090-1095, 2013. https://doi.org/10.1038/ki.2013.248

SKINNER R: Late renal toxicity of treatment for childhood malignancy: risk factors, long-term outcomes, and surveillance. Pediatr Nephrol 33: 215-225, 2018. https://doi.org/10.1007/s00467-017-3662-z

SOLIMAN MM, ATTIA HF, EL-ELLA GA: Genetic and histopathological alterations induced by cypermethrin in rat kidney and liver: Protection by sesame oil. Int J Immunopathol Pharmacol 28: 508-520, 2015. https://doi.org/10.1177/0394632015575950

TOMIMORI N, ROGI T, SHIBATA H: Absorption, distribution, metabolism, and excretion of [(14) C] sesamin in rats. Mol Nutr Food Res 61: 2017. https://doi.org/10.1002/mnfr.201600844

WAN Y, LI H, FU G, CHEN X, CHEN F, XIE M: The relationship of antioxidant components and antioxidant activity of sesame seed oil. J Sci Food Agric 95: 2571-2578, 2015. https://doi.org/10.1002/jsfa.7035

WILMES A, BIELOW C, RANNINGER C, BELLWON P, ASCHAUER L, LIMONCIEL A, CHASSAIGNE H, KRISTL T, AICHE S, HUBER CG, GUILLOU C, HEWITT P, LEONARD MO, DEKANT W, BOIS F, JENNINGS P: Mechanism of cisplatin proximal tubule toxicity revealed by integrating transcriptomics, proteomics, metabolomics and biokinetics. Toxicol In Vitro 30: 117-127, 2015. https://doi.org/10.1016/j.tiv.2014.10.006

ZHU S, PABLA N, TANG C, HE L, DONG Z: DNA damage response in cisplatin-induced nephrotoxicity. Arch Toxicol 89: 2197-2205, 2015. https://doi.org/10.1007/s00204-015-1633-3 